\title{
SEPARATION OF FRESH AND SALINE WATER USING BY INTERPRETATION OF GEOELECTRIC DATA (A CASE STUDY OF ESHTEHARD IN NORTH OF IRAN)
}

\author{
A. Pazoki ${ }^{a^{*}}$, A. Saket ${ }^{\text {b }}$ D. Hariri ${ }^{\text {b }}$ \\ a * Assistant Professor, Faculty of Engineering, Department of Mining, Lorestan University, Iran, e-mail: a_pazoki@yahoo.com \\ $\mathrm{b}$ a faculty member of the Institute of Disaster
}

Received: 27.09.2017 / Accepted: 15.10.2017 / Revised: 10.11.2017 / Available online: 15.12.2017

DOI: $10.1515 /$ jaes-2017-0013

KEY WORDS: separation of fresh and saline water, geoelectric, Eshtehard, village Ipak

\begin{abstract}
:
Groundwater study through the operation of geoelectric, considered one of the best known way in the field. Consideration and accuracy in accurate extraction of water and using the proper equipment and interpret detailed data can reveal high potential of these methods in the best way for underground exploration. This study was conducted to investigate the separation of fresh and saline water, using the analysis and interpretation of geoelectric data collected by the array Schlumberger. Because human needs for fresh water for drinking water, agriculture, animal husbandry and industry, and difficulties in the initial identification layer of saline water in these important activities, find a way to solve these problem is very important. The purpose of case study conducted in southwestern of plains Eshtehard is recognition of border of saltwater and freshwater for wells to provide water for the construction of water wells to water supply for greenhouses exist in the region. In this study, by obtaining data geoelectric and their interpretation, was observed that by increasing the amount of EC (electrical conductivity) due to presence of the solute salts in certain depth of groundwater, sudden drop in specific resistivity be seen in specific range of Probing taken, and according to studies carried out in different regions of the world, these sudden change is known as the boundary separating fresh and saline water, that study and comparison of geophysical data with log obtained from drilled wells in these area, also is a confirmation of these fact.
\end{abstract}

\section{INTRODUCTION}

In lately decades groundwater exploration through understanding and interpretation of Geoelectric data has significantly progress in Iran. One method of geophysics is geoelectric methods. That close to 100 years old (Since 1912 and with the first practical application of these studies by Schlumberger) and during the period after the presentation significant progress has been achieved in these regard. At first only Schlumberger method was used to study Geoelectric. But later depending on the application, accuracy, study depth and defined project, other methods were added to these studies, including Wenner, dipole-dipole, polar-polar and etc. Instruments used in Geoelectric method is included a flow transmitter and harvesting potential difference, transfer wire and potential receptors and the number of electrodes including current and potential electrodes, of brass or copper. First, to better introduce for conventional methods in Geoelectric operations, explanations should be provided about main array of this operation, three main arrays of this geoelectric operations include:

a) Schlumberger array: in this method, two potential electro deallocated between two current electrode, with distance from the center, the distance of the current electrode will show further expansion than the electrode potential. This method is used for exploration in deep and separation of layers at depth.
In these studies, the most commonly depth is $250 \mathrm{~m}$. But sometimes been used up to 500 meters (Ismail \& Ismail, 2005).

b) Wenner array: at Wenner method similar to Schlumberger method, potential electrodes placed within the current electro demand the difference is that changes in distances of current and potential electrodes shall be regulated with a fixed ratio. This method is used to study with more accuracy in less depth (Stummer et.al, 2004).

c) Dipole array: in the dipole method, potential electrodes locate outside the current electrodes and applying this approach more to areas that have a high environmental noise and the operation requires to rigor in shallow depth and investigate lateral variations (Stummer et.al, 2004) (Figure 1).

\section{MATERIAL AND METHODS}

\subsection{The aim of the study}

In this study, according to the intended purpose, means the separation of fresh and saline water-bearing layers the array Schlumberger was used. . The reason for using this array is high efficiency of this method in separate layers deep. It should be noted that in order to increase accuracy in order to harvest the geoelectric data should be considered specific arrangements in 
an area with water reserves saturated by minerals, and distinguishing this other layer.

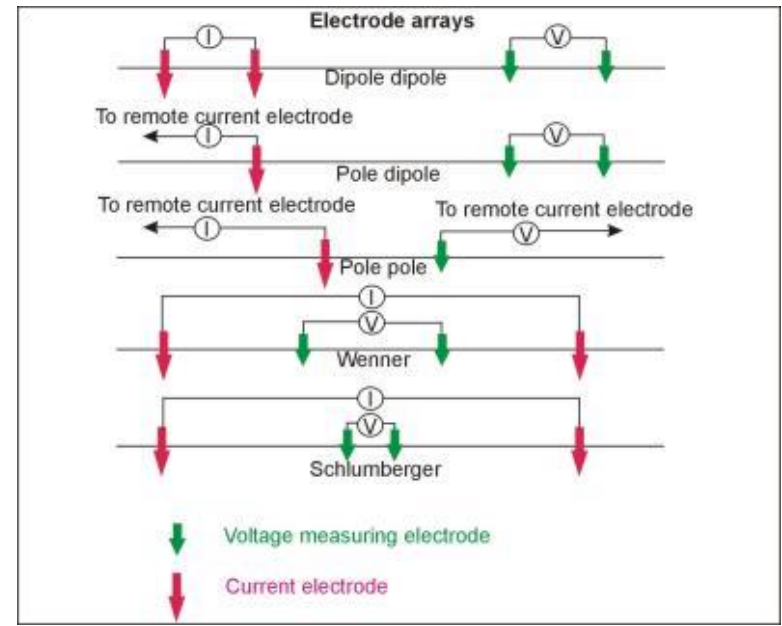

Figure 1. The placement method of the electrodes in Geoelectrical Studies (major and minor ways)

That can be mentioned: choose a device with high output power and the possibility of changing the current administration in terms of frequency, use of measure cables with minimal electrical resistance and use of electrodes with a thickness greater than $15 \mathrm{~mm}$ of copper (because it reduces the degree of polarization). Non-compliance, reduced ratio of signal to noise in study area and causes an error in determining the precise boundary of fresh and saline water.

\subsection{Discuss}

Geographical and geological characteristics of the area: The study area is located near the village of IPAC in the southern city Eshtehard of functions Alborz Province. As shown in Figure 2 (map available) is depicted, this area of the city of Karaj is available in two forms: village of Ipack Eshethard - Safadasht - Mahdsht - Karajand also village of Ipack - Eshethard - Nazarabad - Hashtgerd - Karaj. End of road (Eshethard to Ipack) part of route is asphalted and the rest of route is dirt track. To achieve the desired range to pass important part of igneous outcrop of area (Eocene).

In the same way, there are certain types of volcanic rocks made of trachyte, andesite and basaltic andesite (Saket et al., 2008) (Figure 2).

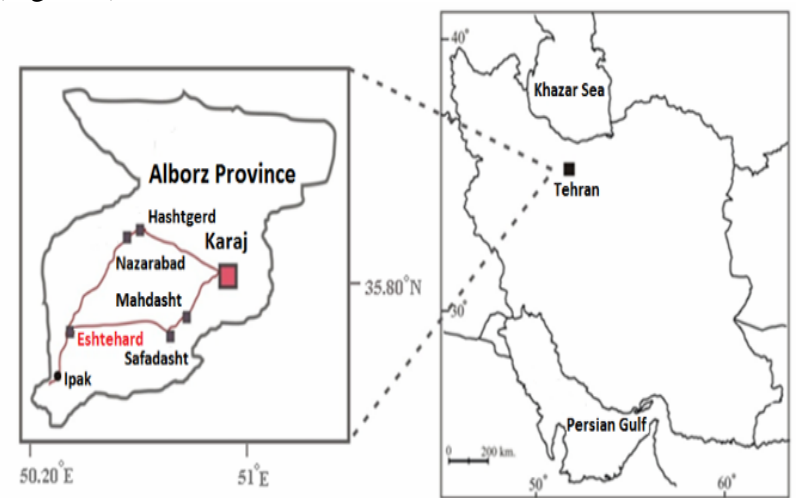

Figure 2. Map of access roads to the area
The study area is a geological 100000/1mapofEshtehard and is surrounded to the north by Eocene volcanic structures in the region (Figure 3).

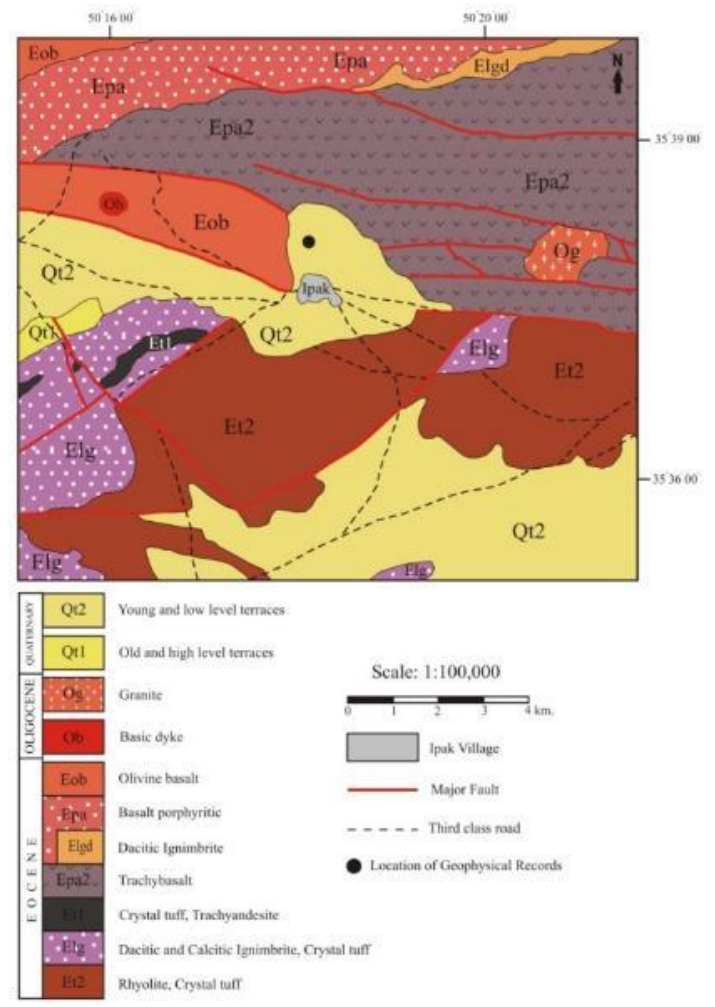

Figure 3. Geological map 1/100000 of Eshtehard and study area in the center of the map (Geological Survey of Iran)

Fault southern Eshtehardis one of influencing factors in region roughness, that is of kind of pressure and is considered for it south-facing slope with lateral displacement.

This pressure and young fault with relative length of 55 kilometers and from east to west to Eshtehard Mahdasht. Karaj Mahdsht - fault with fault south of bees in a process and a total length of $80 \mathrm{~km}$ From the West has come to Eshtehard and from the East to Mahdasht. Karaj-Mahdsht fault with south fault of Eshtehard had been in a process and total of their length is 80 $\mathrm{km}$. Existence formations of tertiary in the region and influence of water-bearing layers of this formation, has caused changes in the quality and quantity of aquifers in region. That this study based on collected data, have been mentioned to how these effects.

Following review of literature based on the separation of fresh and saline water, taking into the consideration of Geo-electric studies related to fresh and saline water separation is dedicated to coastal regions due to the importance of discussion and incorporation of fresh and saline water which is considered as an unplanned harvesting in these areas.

The water intervention in some part of black sea in proximity of Romania coasts is studied (Georgescu and et al, 2010). In this study, the Geo-electric operations could have presented the proper estimation related to the identification and demarcation of mixing fresh and salt water. 
Considering to this process, they have used data gathered by well location in these regions and results are taken from Geoelectric data. A similar study has investigated watersheds and coastal areas for the purpose of freshwater resources management in India (Ezhisaivallabi and Poongothai, 2016). Taking into consideration of mentioned investigation, Nowroozi et al, 1999 draw our attention into the fresh and saline separation in the coastal areas of U.S.

Some studies have been conducted to evaluate the quality and quantity of groundwater in the range of Eshtehard and surrounding areas, by the Department of Rural Water District. These studies had some good results, but in some cases due to the lack of compliance and comparing geological data with geophysical data errors have followed (Saket and Hariri, 1387). As previously mentioned, geoelectric studies on groundwater issues in Iran and other parts of the world have been widely carried out that some of these studies include: groundwater study using two-dimensional electrical tomography (Hallajfard and Bagheri, 2011); the application of electrical method of certain resistivity in exploration of groundwater in karst areas (Nakhaei, 1992); evaluation of soil profile in aquifer layers using by geoelectric method (Alile et.al, 2007); Non-linear evaluation of aquifer parameters using electrical resistance measurements on the surface (Singh, 2005); Geoelectrical study to assess groundwater conditions (Lashkaripour and Nakhaei, 2005) and numerous other studies. However, studies indicate that the purpose of this article except as limited, is not addressed specifically targeted (Frohlich \& Urish, 2002), (Stumm \& Chu, 2003) and (Saket et al., 2007).

Based on geoelectric data can be used of specifications change of harvested data to separate the fresh and saline for resistance in different parts.

For example (Stumm \& Chu, 2003) in study project of ground water in New York area which was carried out at the United States Geological Survey (USGS) was shown that by studying of certain variations in resistance can be engaged to identify the level of saline groundwater and also to separate salt water from fresh (Figure 4). Also, Egbai and Efeya, 2013, presented an important study in Nigeria. They used recorded direct information of graph and data for their interpretation.

In the study area based on geology, topography and the structure were selected 10 points, in an area of 4 ha and interpret data related to these points have been used to present data related to groundwater studies.

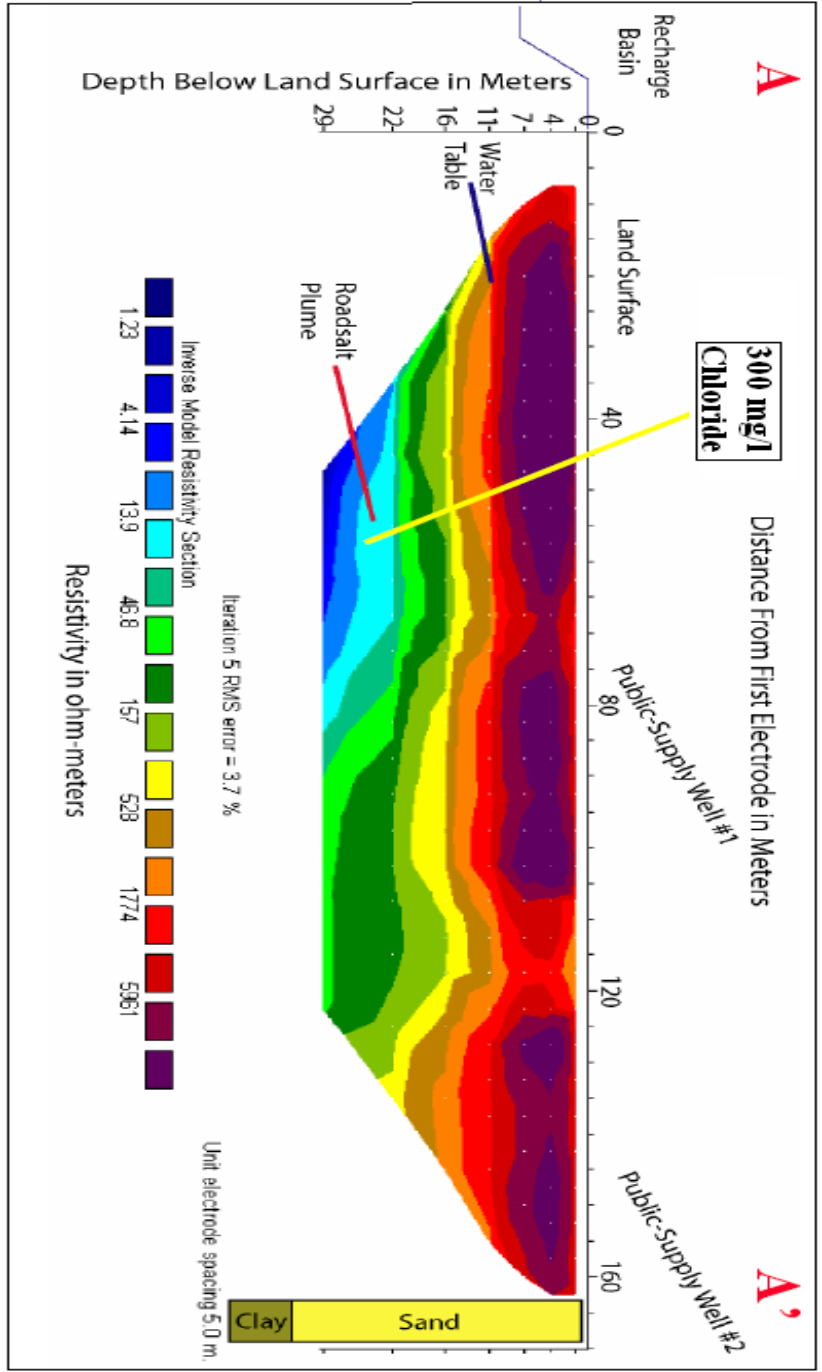

Figure 4. The groundwater level and layer that has a certain salinity layer in below the surface of the water by harvesting Geoelectric (Stumm \& Chu, 2003)

Place of the harvested points in geoelectric operations in Figure 5 on satellite photos of region were provided. In this figure, the highlands of the northern part of the region clearly indicates that represents the igneous rocks outcrop to Eocene. 


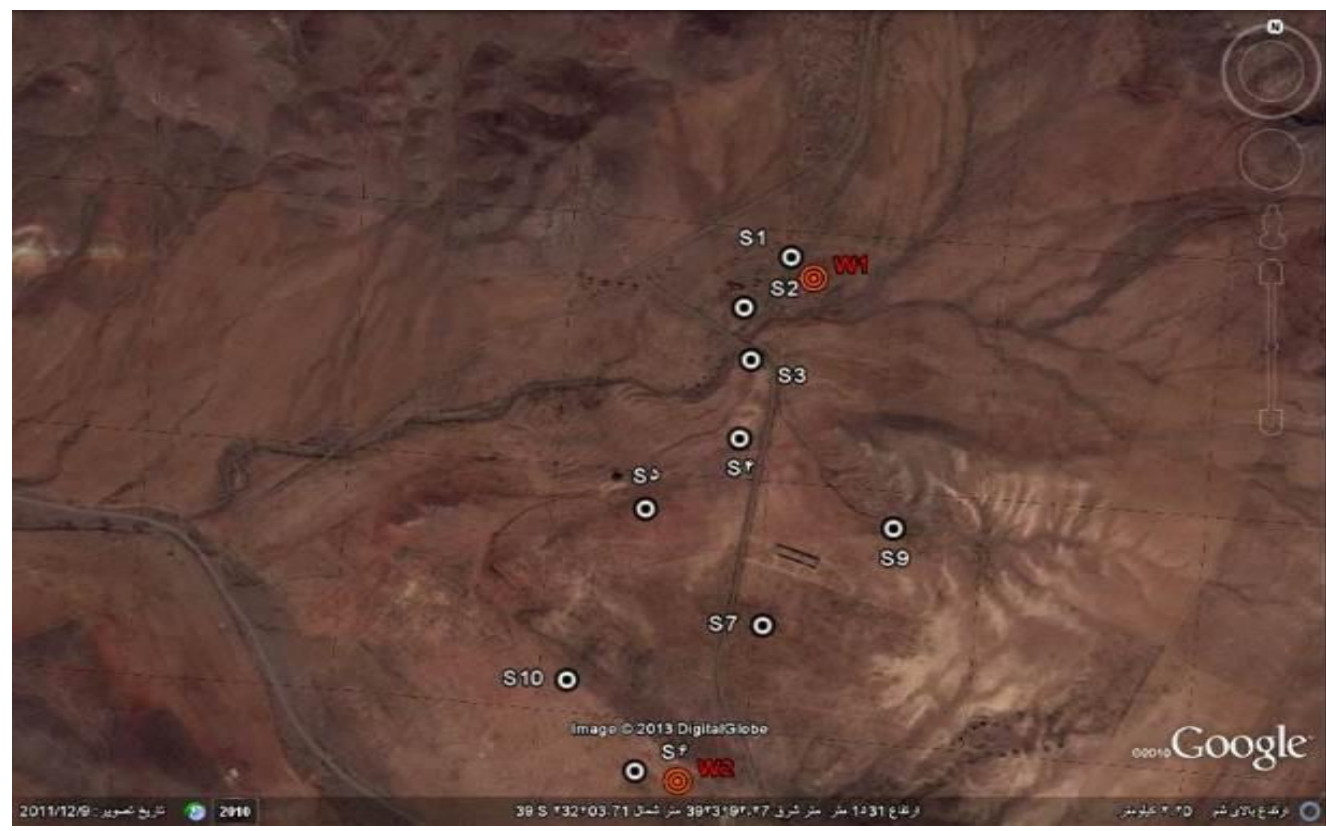

Figure 5. The location of harvested geoelectric Probing (marked with the letter S) and drilled wells in the region (marked with the letter W) on satellite photos

\subsection{Methods}

In the analysis and interpretation of geoelectric data collected, IPI2 and Surfer software are used. Among the important features of results and figures are extracted from these software can be noted to border incremental for layers that many compliance with the conditions of sedimentation and gradual conversion layer in terms of the type of lithology. Based on excavations to reach ground water, marked differences in water quality in the region is evident that proper compliance have with the probing interpretation of the range. It should be noted that another study about the impact of composition and structure of region geological on groundwater quality related to part of northeast of Eshtehard plains (Saket et al., 2008).

In this study, more accurate and better data to compare, probing groundwater that was in same direction was placed in a profile and was analyzed. For direction each profile, transverse pseudo cross-sections of transverse resistivity (Figures 6 to 10) were obtained, that is showing how resistivity distribution at place of each probing in depth, obtained by the application IPI2.

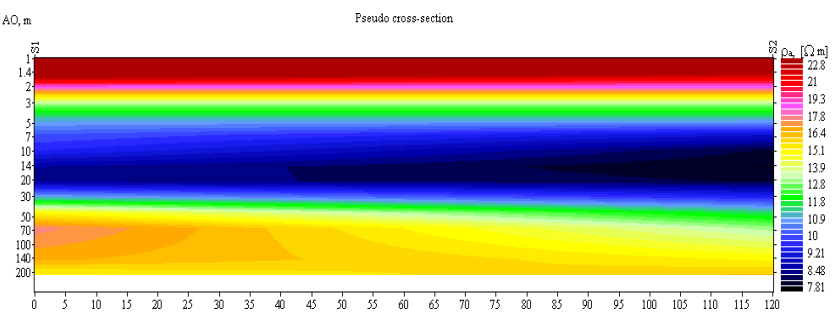

Figure 6. Transverse pseudo cross-sections of profiles are provided for points 1 and 2

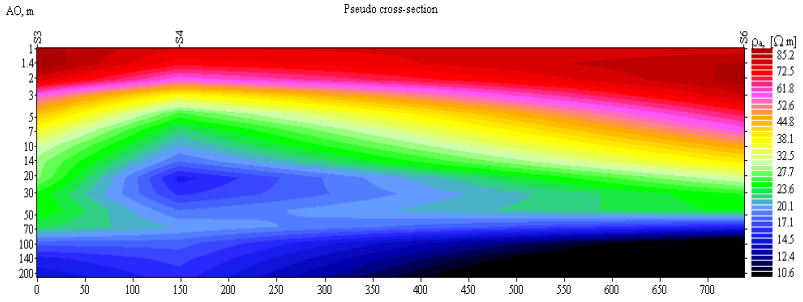

Figure 7. Transverse pseudo cross-sections of profiles are provided for points 3,4 and 6

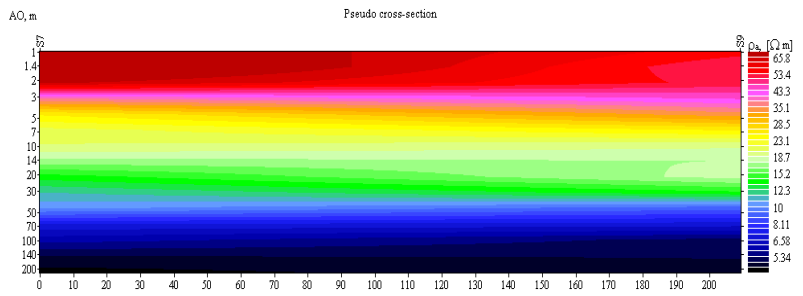

Figure 8. Transverse pseudo cross-sections of profiles are provided for points 9 and 7

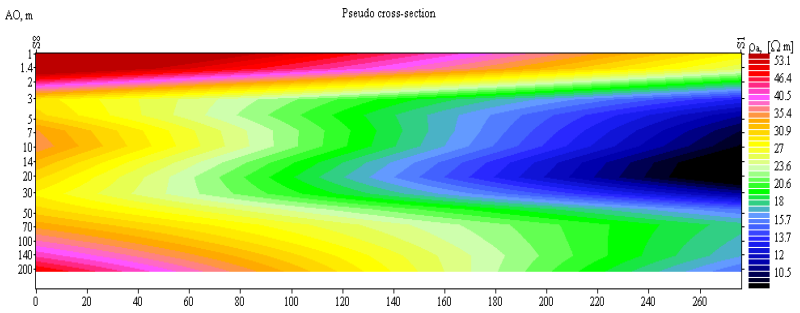

Figure 9. Transverse pseudo cross-sections of profiles are provided for points 1 and 8 


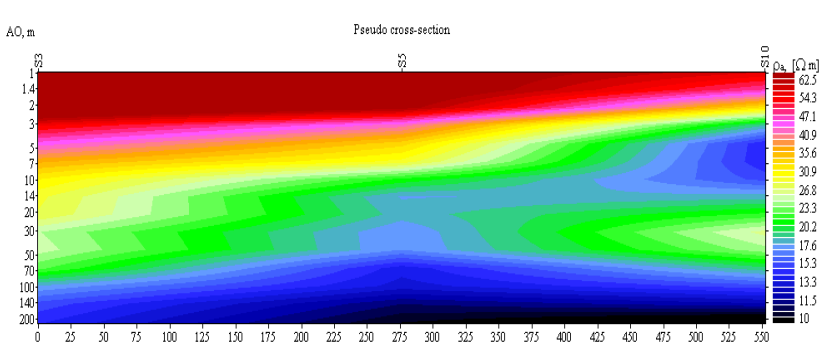

Figure 10. Transverse pseudo cross-sections of profiles are provided for points 3,5 and 10

Through analyzing the sub-sections obtained in this study, the following is available:

In probing 6, 7 and 9 in particular in Figures 7 and 8, are shown effect of subsurface formations by penetration of salt and gypsum layers for dark colors. During the profiles that have been stretched to the southern areas, and have distanced themselves from the heights of igneous, and consequently have surrounded greater sediment thickness (Figure 7 respectively of the probing 3 to 4 and 6, Figure 9, the probing 1 to 8 and Figure 10 of the probing 3 to 5 and 10), influence salt layers of sediment is clearly in the downstream. Also emergence of layers of volcanic rocks precisely defined in upper area (points 1 and 2 ), In Figure 6, increasing depths greater resistance to demonstrate the existence of hard layers of igneous At that point, and that proximity of the high points of igneous rocks in the northern endorses this claim. In studies conducted, according to the resistivity changes in harvested areas, and compliance information in the area, reducing resistance show existence hydrated salt layer of sediments in the deep in some spots (harvested areas downstream) which is a concrete quality of reduced water quality in this area. The studies conducted in this study and relevant evidence that will be presented in the following, the resistance of salt water layer is considered less than $11 \mathrm{ohm}-\mathrm{m}$. The resistance was chosen because, graph obtained corresponds to the data collected and resistance suddenly drops over the same number and cases have clearly illustrated this by changing the color associated with existing profiles. For example, probing No.6 (Figure 7) is shown in the real depth of 35 to 40 meters. Changes color from blue to black (darker color) is clearly marked.

Regarding to the previous studies, Islami (2011) using Geoelectronic operation in underground water reservoir in north of Indonesia showed that the boundary of fresh and saline water is estimated $7 \mathrm{ohm}$. Also Mogen (2015) have considered saline water resistance is estimated 10 meter in related to results during Geo-electronic process in the coastal areas in Red sea in Arabic country.

The represented resistances aren't mentioned in using water at agriculture. So saline water is considered by articles only have 0-1 ohm meter resistance. In these environments, not only saline water is highly mentioned, but also very fine-grained sediments with high electrical conductivity, such as clay play an important role in strata. These conditions lead to severe decrease of electric resistance in strata (Ezhisaivallabi and Poongothai, 2016; Satriani et al., 2011). Considering to this process, it is concluded that results which have focused on identifying saline water resistance and separating it from watery layers with less salty ones, are similar to preliminary studies in the other region of the world. As a result the methodology is validated.

To confirm this, should be noted that depth approach to saltwater during the excavation area, near probing No.6 declared about 35 to 40 meters. That exactly is in compliance with the interpretation of geophysical surveys at this point as well as compliance with a study that has introduced deep into the layers of salty water. Therefore, only probing in 1,2, 3 and 4 to a depth of 80 meters and more water quality was moderate to good. But in harvested areas 6, 7, 9 and 10, there is a decrease in water quality at depths between 35 to 90 meters that this decrease of more than 10 points has shown in points 6 and 7 and 9. It can be said, this case is of great relevance to the position of separated points in north and south of the study area, that quality of water in them is proper and improper, respectively. Also in Fig. 11 concerns the pseudo cross section in North - South direction of Region that in this figure changes in bond strength and their position relative to each other is depicted. In this figure, the emergence of low-resistance layer (layer of salt water) as well as it can be seen clearly in the lower right corner (on the southern part of the range). The presence of intrusive rocks with higher resistance at the bottom left of the picture (on the north of 9) in points 1 and 2 are well separated.

In Figure 11 clearly shows that the most unfavorable point is to drill points (7) and because it climb salt layer to upwards (at a depth of 30 to 35 meters below the surface) by faults in this range. In Figure 11, marked the position of the fault causing the salt mass movement in underground with line and boundary layers to separate the relevant faultshows the high accuracy of geophysical data for the breakdown subsurface geological structures.

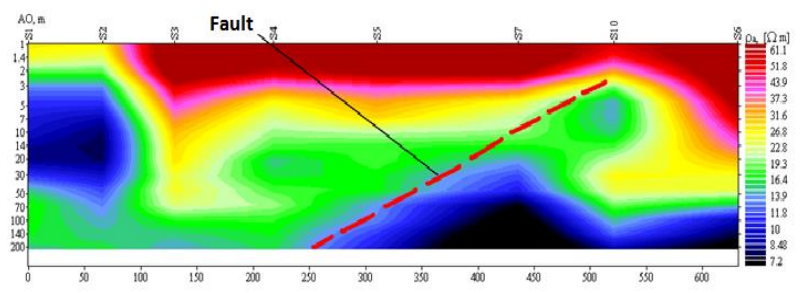

Figure 11. Quasi-cross of harvested points in the north-south direction (from left to right) fault causing the uplift salt layer

It should be noted conducted numerous articles in the field of structural geology indices including fault (Vallianatos \& Markis, 2000). Also, as in the figure (Figure 11) is visible (at least to a depth of $70 \mathrm{~m}$ ), were selected as the most appropriate point for excavation because point 4 is not dealt with salt layer. For better visualization of this case, map of resistance to four specific depth $(21,34,50$ and $73 \mathrm{~m})$ for all probing harvest is depicted in Figure 9, that declining water quality can be seen with darker color in the upper left corner map. And this shows the harvest points in the southern region, means probing 6,7 and 9 (in the 12 northern and southern boundaries, is shown at right and left map, respectively). Thus, as previously mentioned, in the right half of the image (which corresponds to probing positions 1, 2, 3 and 4) water quality has improved more indepth and in the left half which indicates the position of probing $6,7,9$ and 10 , water quality is low. 
This case shows that the water quality is better than probing low in harvested probing in the upstream of study area, as can be seen in Figure 12.

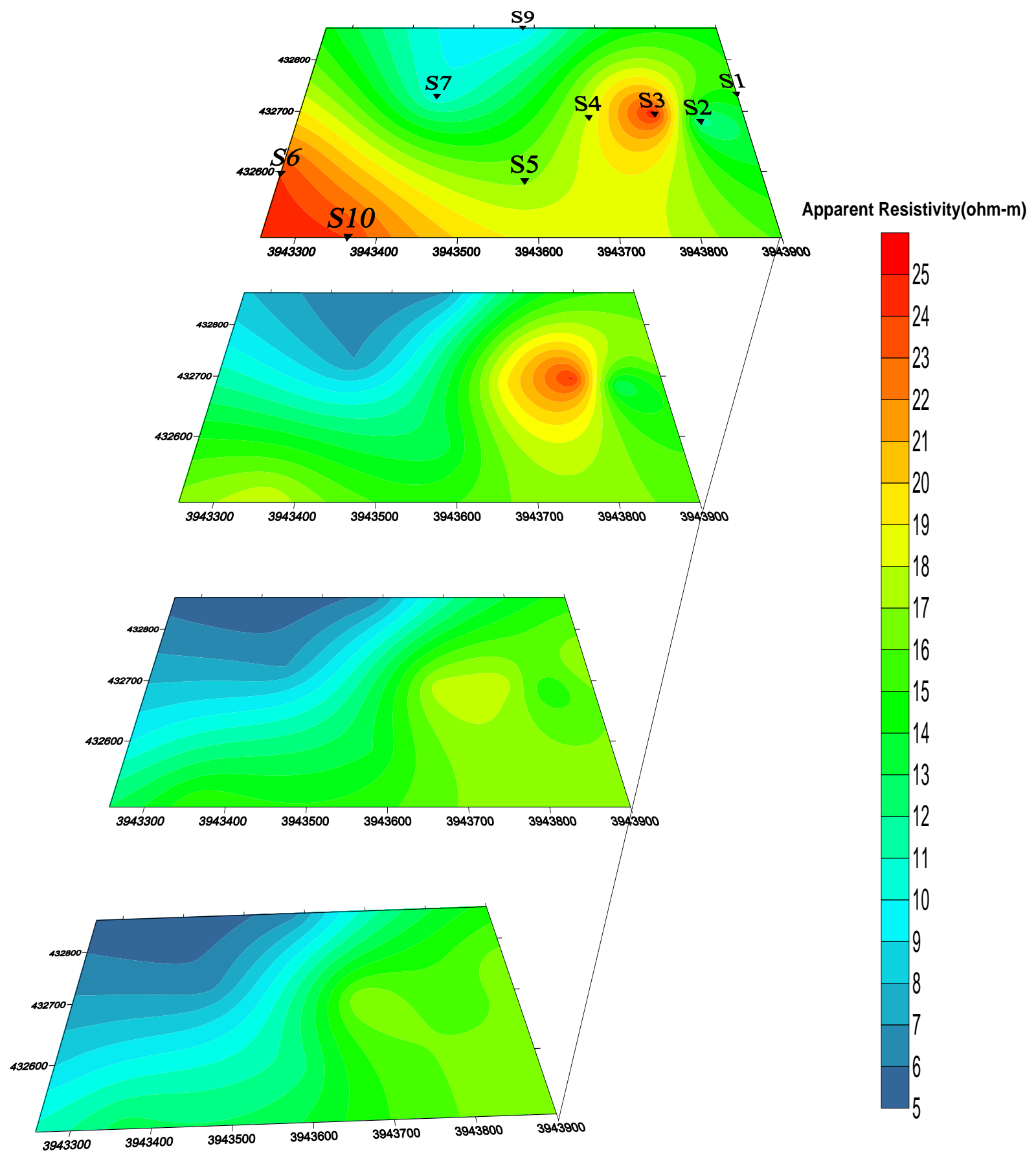

Figure 12. Depth map of electric resistance for depths of 21, 34, 50 and 73 meters from top to bottom, respectively

And as previously mentioned, composition and type of rock structure will have a large impact on the quality of underground water. Since the upstream region have appeared in Eocene volcanic outcrop can in terms of geology be also confirmed this conclusion that in the upstream area of water quality is better because of the volcanic layers with low solubility, and cropped salt formation with a high solubility, have a significant impact on groundwater quality in downstream areas. Finally was prepared geology section of the study area, based on harvest geophysical data, field surveys of geologists as well as data related to observation wells (Figure 13). 


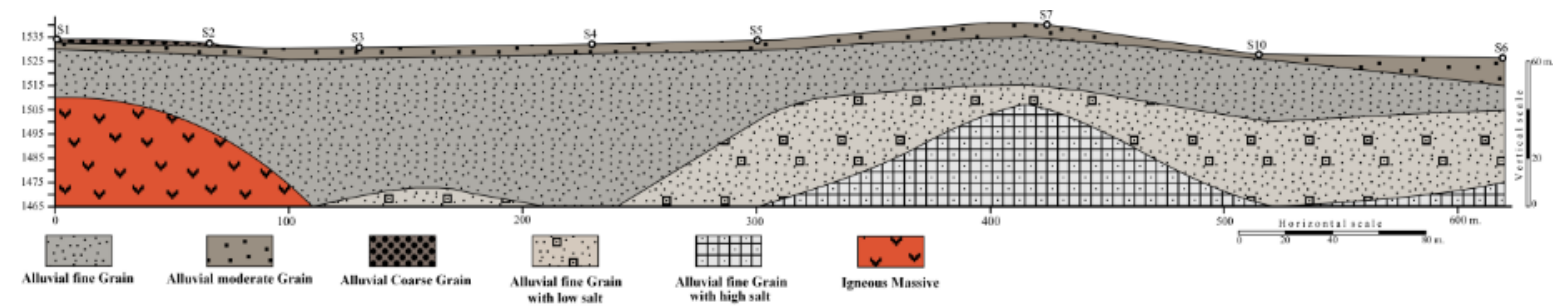

Figure 13. Geological cross-sections obtained based on harvest available data

As can be seen in Figure 13, mass of igneous intrusion in north of region who was harvested in geophysical probing of 1 and 2 (S1, S2) has been found in the northern area (left figure). And also in the southern part of the area (right half of the figure) has been shown dome shape, influence masses which has a high percentage of salt.

\section{CONCLUSION}

- Changes in electrical resistance can be used as a convenient guide and applied in the diagnosis of water quality that changes of resistance are available through Geoelectrical Studies.

- Geological composition and structure can have a large effect on the quality of underground water and since the Earth's formation can be traced using geoelectric studies, in this way, apart from boundary determination for fresh and saline water can be realized to a large extent to the development of underground geological formations. So be careful in Geoelectric operations in the understanding and interpretation of data can provide specifications between geological and geophysical data that combination of these two categories will be too many points in the basic studies in this field.

Data related to drilled wells were compared with Geo-physics to approve operations. Data were perfectly demonstrated to approve Geo electric operations based on data gathered in the real time in mentioned region.

- According to the results obtained in this article and the interpretation of geophysical data and sudden drop of strength in depth certain harvested areas, boundary between fresh and saline water were detected, so this could be a good model for the study of such projects in other regions used.

- The availability of faults is one of the other important items that by careful analysis can be realized that they exist in subsurface layers. And these were considered in this study and were properly identified.

\section{REFERENCES}

Alile O.M., Molindo W.A., Nwachokor M.A., 2007. Evaluation of soil profile on aquifer layer of three locations in Edo state, International Journal of physical science Vol 2, pp. 249-253.

Egbai J.c, Efeya Pios, 2013. Geoelectric method for investigating salt water intrusion into freshwater aquifer in Deghele community of Warri south local government area of Delta state, Technical Journal of Engineering and Applied Science., ISSN 2051-0853, pp. 819-827.
Ezhisaivallab K. and Poongothai S., 2016. Geoelectrical signatures of the coastal aquifer system of Adappa watershed. International Journal of Chem Tech Research. ISSN: 09744290. Vol 9. N0.06. pp. 67-613.

Frohlich R., Urish D., 2002. The use of geoelectrics and test wells for the assessment of groundwater quality of a coastal industrial site, Journal of applied geophysics, pp. 261-278.

Georgescu Paul, Loane Dumitru, Niculescu Bogdan Mihai, Chitea Florina, 2010. Geoelectrical investigations on marine intrusions on the Romania Black Sea shore, Geo-Eco-Marine. Volume 16. pp. 85-92.

Hallajfard A., Bagheri A., 2011. Characterization of an aquifer using electric two-dimensional tomographic. The thirtieth meeting of Earth Sciences.

Ismail M., Ismail M., Electrical resistivity investigation at Nuweiba harbor Gulf of Aqaba, South Sinai, Egypt, Egyptial Journal of Aquatic Research Vol. 31, 1, ISSN 1110-0354.

Islami Nur, 2011. Geoelectrical resistivity method for salt/brackish water mapping. Journal of Coastal Development. Volume 14. Number 2, pp. 104-114.

Lashkaripour G., Nakhaei M., 2005. Geoelectrical investigation for the assessment of groundwater conditions: a case study. ANNALS OF GEOPHYSICS, VOL. 48, No 6.

Mogren Saad, 2015. Saltwater intrusion in Jizan coastal zone, southwest Saudi Arabia, Inferred from geoelectric resistivity survey, International Journal of Geoscience, Volume 6, pp. 286297.

Nakhaei M., 1992. the application of electrical resistivity method exploration ground water in areas of karst, Shiraz University, Department of Geology, MSc thesis.

Nowroozi A.A., Horrocks S.B. and Henderson P., 1999. Saltwater intrusion into the freshwater aquifer in the eastern shore of Virginia: a reconnaissance electrical resistivity survey, J. of Applied Geophysics, Vol. 42, pp. 1-22.

Saket A., Hariri D., 2008. Statements of Geoelectrical operation near the Ipak village near the city Eshtehard of Tehran province. Peysang Consulting Engineers.

Saket A., Hariri D., Kardan R., Fahimy M., 2007. Study the effects of salt deposits and chalk on ground water using geoelectric data interpretation, case study Eshtehard plain, the Fifth Conference on Engineering Geology. 
Satriani A, Loperte A, Proto M., 2011. Electrical resistivity tomography for coastal salt water intrusion characterization along the Ionian coast of Basilicata region (Southern Italy), Fifteenth International Water Technology Conference, IWTC15, Alexandria, Egypt.

Singh K.P., 2005. Nonlinear estimation of aquifer parameters from surficial resistivity measurements, Hydrol. Earth Sys. Sci. Discuss, 2, pp. 917-938.

Stummer P., Maurer H., Green A.G., 2004. Experimental design: Electrical resistivity data sets that provide optimum subsurface information GEOPHYSICS, VOL. 69, NO. 1, pp. 120-139, 13 FIGS. 10.1190/1.1649381.

Stumm F., Chu A., 2003. Application of Advanced Surface and Borehole Geophysical Methods to Hydrogeologic Studies on Long Islandand New York city, U. S. Geological Survey Water Science Center Coram.

Vallianatos F., Markis J., 2000. On the tectono-electric zonation in the Helenic arc, Phys. Chem. Earth (A), Vol 25, No 3, pp. 307-313.

Yousefi M., Geological map 1/100000 of Eshtehard, published by Geological Organization and Mineral Exploration Survey of Country. 